American Journal of Applied Sciences 6 (8): 1626-1632, 2009

ISSN 1546-9239

(C) 2009 Science Publications

\title{
Voltage Sag Effects on the Process Continuity of a Refinery with Induction Motors Loads
}

\author{
${ }^{1}$ Tarek I. ElShennawy, ${ }^{2}$ Mahmoud A. El-Gammal and ${ }^{2}$ Amr Y. Abou-Ghazala \\ ${ }^{1}$ Alexandria National Refining and Petrochemical Co., \\ El-Sad El-Aaly St., Wady El-Kamar, El-Max, Zip Code: 23111, Alexandria, Egypt \\ ${ }^{2}$ Department of Electrical Power Engineering, Faculty of Engineering, \\ Alexandria University, Alexandria, Egypt
}

\begin{abstract}
Problem statement: Process continuity of industrial plants (like a refinery) is subjected to several shutdowns due to voltage sags causing large induction motors to trip, either by undervoltage or by overcurrent relays, sometimes by the mechanical protection. These unplanned shutdowns cost the plant tens of thousands of dollars per shutdown in addition to material damage costs, restart charges and any penalties due to delay in product delivery and shipping. Approach: The behavior of induction motors during voltage sags was investigated. In addition to the well-known parameters of voltage sags (time and duration), other parameters such as three-phase unbalance, point on the wave of sag occurrence, harmonics, loading percentage and pre-sag voltage were also examined through computer simulations using the MATLAB/SIMULINK toolbox. Motors' ride-through capability during sags was also studied and guidelines for adjusting the protection relays of the induction motors were highlighted. Results: Results showed that response of induction motor to voltage sags is dependant on sag characteristics, as well as motor and load parameters. Three-phase voltage sags and sags occurring at zero crossing were the most severe events. Transient currents occurring at the instants of voltage sag and voltage recovery are directly proportional to the voltage drop, not to the remaining voltage magnitude. Transient currents and torques induced at the instant of sag recovery are higher than those induced at the instant of sag occurrence. Lightly-loaded motors and motors operated at voltages higher than the nominal voltage are less affected by voltage sags. Conclusion: Manufacturers of induction motors impose strict protection settings to protect their machines from any possible damage. However, the starting process of the motor inherits starting currents and torques much higher than those occurring during voltage sags. Readjusting of the protection relay settings especially the undervoltage relay may be adequate to counteract voltage sags. No conditioning equipment was required.
\end{abstract}

Key words: Power Quality (PQ), voltage sags, Induction Motor (IM)

\section{INTRODUCTION}

Alexandria National Refining and Petrochemicals Co. (ANRPC) is a refinery based in Alexandria, Egypt, with an average load of $10 \mathrm{MW}$. About $80 \%$ of the load consists of induction motors. The plant suffers from several voltage sags due to transmission system faults as well as faults from neighboring customers on the common distribution system. Although lasting for durations in the range of a quarter second to barely more than $1 \mathrm{sec}$, these voltage sags cause large induction motors connected directly to the supply bus to trip, either by under voltage or by over current relays, sometimes by the mechanical protection.
These unplanned shutdowns cost the plant tens of thousands of dollars for each shutdown in addition to material damage costs, restart charges and any penalties due to delay in product delivery and shipping.

The company asks for the advice of the faculty of engineering and a joint group was formed from the faculty consultants and the electrical engineers at the company to thoroughly investigate and recommend solutions for this problem. This study is part of this research study.

Voltage sags and induction motors: The IEEE defines voltage sag as: A decrease to between 0.1 and 0.9 p.u. in rms voltage or current at the power frequency for durations of 0.5 cycle to $1 \mathrm{~min}$. The amplitude of

Corresponding Author: Tarek I. ElShennawy, Alexandria National Refining and Petrochemical Co., El-Sad El-Aaly St., Wady El-Kamar, El-Max, Zip Code: 23111, Alexandria, Egypt 
voltage sag is the value of the remaining voltage during the $\operatorname{sag}^{[1]}$.

The IEC terminology for voltage sag is dip. The IEC defines voltage dip as: A sudden reduction of the voltage at a point in the electrical system, followed by voltage recovery after a short period of time, from half a cycle to a few seconds. The amplitude of a voltage dip is defined as the difference between the voltage during the voltage dip and the nominal voltage of the system expressed as a percentage of the nominal voltage ${ }^{[2]}$.

Figure 1 shows an rms representation of voltage sag, the sag starts when the voltage decreases to lower than the threshold voltage Vthr $(0.9$ p.u. $)$ at time T1. The sag continues till $\mathrm{T} 2$ at which the voltage recovers to a value over the threshold value, hence the duration of the voltage sag is (T2-T1) and the magnitude of the voltage sag is sag to $\mathrm{Vsag}^{[3]}$.

Effects of voltage sags on IMs: As the supply voltage to the induction motor decreases, the motor speed decreases. Depending on the depth and the duration of the voltage sag, the motor speed may recover to its normal value as the voltage amplitude recovers. Otherwise, the motor may stall. Responding in either case depends on the motor parameters and the torquespeed characteristic of the driven load ${ }^{[4]}$.

Figure 2 shows three different torque speed characteristics of an IM, along with a constant load torque. Curve A shows this relation during normal conditions. Voltage sag will reduce the motor torque proportional to the square of the motor terminal voltage. The IM may undergo a limited amount of retardation and may be able to reaccelerate on voltage recovery, as shown in curve B. Otherwise, the electric torque produced by the IM may become less than that of the load, the IM may decelerate and the continuity of the output may be lost, as shown in curve $C^{[5]}$.

Effects of voltage recovery on IMs: Reapplication of out of phase voltage to a motor with a strong remaining rotor field may result in electromagnetic and shaft torque and current transients which may approach starting values. It must be decided whether to allow voltage to be reapplied to the motor terminals at whatever instant it is restored (often with the motor still running and the field still active), or to block reapplication of power until the rotor field has a chance to decay. Depending upon the initial speed loss and the magnitude of the recovery voltage after fault clearance, the motors may accelerate. These accelerating currents, flowing together through the supply system impedance, may prevent a fast recovery of voltage. The stronger the electrical system in relation to the size of the accelerating motors, the greater is the power available for the motors to accelerate and recover ${ }^{[6]}$.

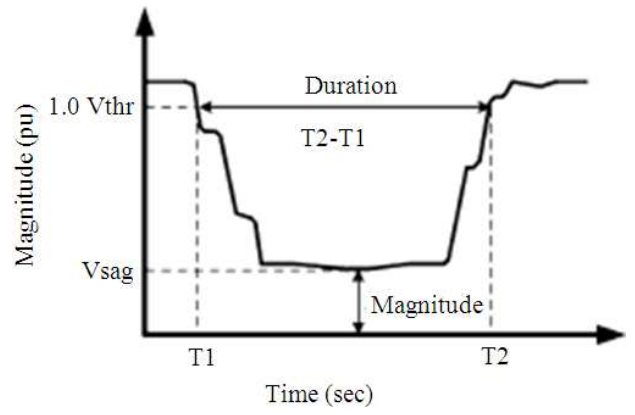

Fig. 1: Voltage sag

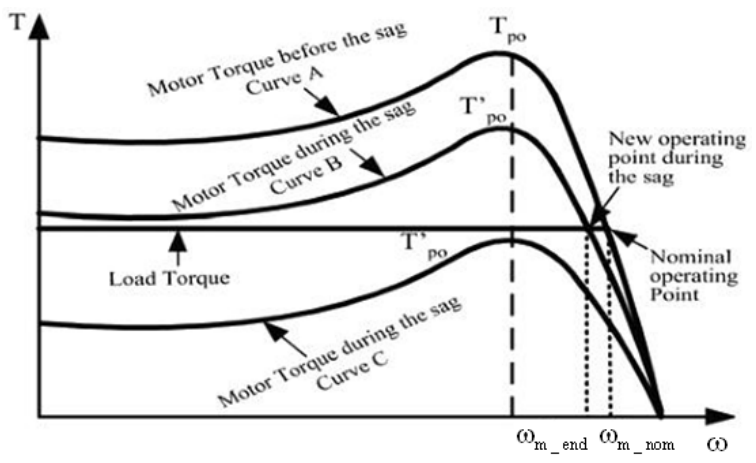

Fig. 2: Motor and load torques before and during different sags

Effects of protection setting on motor performance: Motor recovering process after voltage sags is dynamically similar to motor starting process and is accompanied by large inrush currents. Depending on motor protection settings, these currents can trigger over current protection of the motor resulting in the tripping of the motor. Mechanical protection also can trip the motor if the motor torque becomes incapable of driving the load or if the transient torques after voltage recovery are too high.

Most of IM protection settings are too conservative. This leaves room for adjusting these settings without causing any threat to the motor safety. Many of the unnecessary motor tripping incidents can be avoided by simple adjustment to the motor protection settings ${ }^{[7]}$.

\section{MATERIALS AND METHODS}

Test circuit: The test circuit consists of a voltage source adjusted to simulate voltage sags with pre-determined magnitudes and durations affecting an induction motor, which drives a compressor load. The load torque starts from a constant value of 2000 N.m and then increases gradually in direct proportion to the speed, till it reaches its full load value (about $80 \%$ of motor torque). 


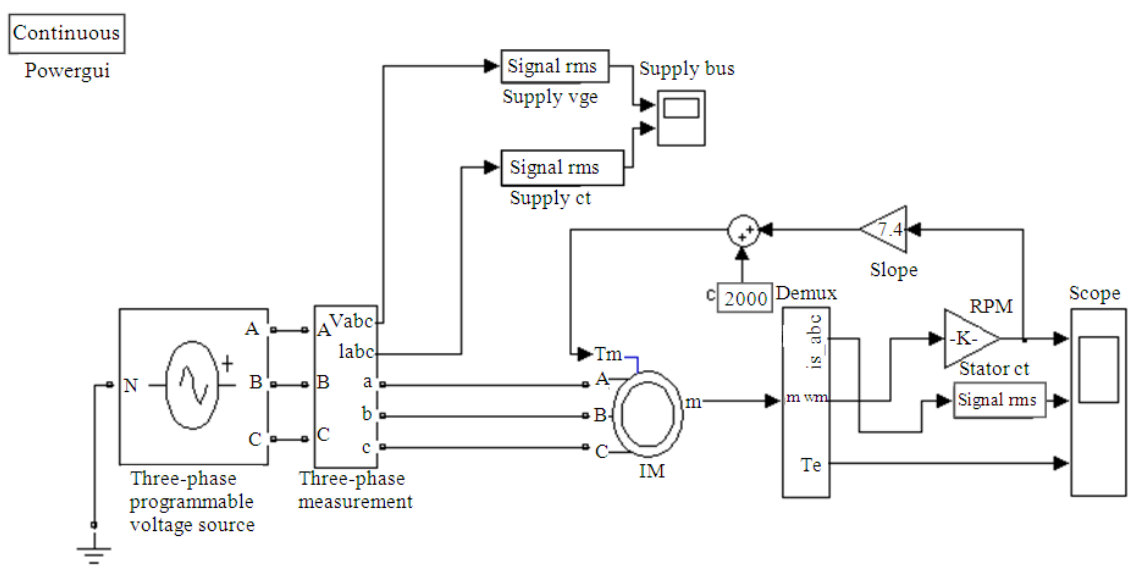

Fig. 3: Simulink model for the test circuit

Table 1: Motor parameters

\begin{tabular}{llll}
\hline Motor parameters & & & \\
\hline Rated power & $2500 \mathrm{~kW}$ & Moment of inertia & $560 \mathrm{~kg} . \mathrm{m}^{2}$ \\
Rated voltage & $11000 \mathrm{~V}$ & Rated Torque (T) & $15959 \mathrm{~N} . \mathrm{m}$ \\
Frequency & $50 \mathrm{~Hz}$ & Locked rotor torque & $75 \%$ \\
Full load current & $153 \mathrm{~A}$ & Pull up torque & $65 \%$ \\
RPM & 1496 & Breakdown torque & $270 \%$ \\
Starting current & $600 \% \mathrm{FLC}$ & Stator resistance & $0.42 \Omega$ \\
Starting time & $22 \mathrm{sec}$ & Stator reactance & $2.73 \Omega$ \\
Locked rotor PF & 0.15 & Rotor resistance & $0.62 \Omega$ \\
Power factor & 0.9 & Rotor reactance & $4.1 \Omega$ \\
Efficiency & $95.5 \%$ & Magnetizing reactance & $197.8 \Omega$ \\
\hline
\end{tabular}

Table 2: Load parameters

Compressor parameters

\begin{tabular}{ll}
\hline Maximum absorbed power & $2057 \mathrm{~kW}$ \\
Maximum torque & $13092 \mathrm{~N} \cdot \mathrm{m}$ \\
Starting torque & $1960 \mathrm{~N} \cdot \mathrm{m}$ \\
Moment of inertia & $1000 \mathrm{~kg} \cdot \mathrm{m}^{2}$ \\
\hline
\end{tabular}

Table 3: Motor protection settings

\begin{tabular}{ll}
\hline Over current setting & $168 \mathrm{~A}$ \\
Time & Inverse \\
Under voltage & $0.8 \mathrm{p} . \mathrm{u}$. \\
Time & $1 \mathrm{sec}$ \\
Mechanical speed loss & 0.95 p.u. \\
\hline
\end{tabular}

Figure 3 shows the implementation of a simple power system in the SimPowerSystems Blockset in the MATLAB workspace. The motor and load parameters are given in Table 1 and 2 and the protection relays settings are given in Table 3 respectively.

\section{Test procedure:}

- The motor is operated with normal (no sag) conditions. From this step, we can quantify the transient currents and torques that the motor is subjected to during starting

- A three-phase voltage sag is simulated with magnitude and duration equal to the existing settings of the undervoltage relay. From this step we can see the actual transient current and torque the motor is subjected to before tripped by the undervoltage protection

- The IM is subjected to a set of voltage sags in all three phases at different magnitudes (ranging from 0.1 p.u. to the voltage sag threshold of 0.9 p.u.) with a step of 0.05 p.u. and for each sag value the duration is incremented gradually till the motor trips by overcurrent or locked rotor or mechanical protection relays. The undervoltage relay is removed from the circuit. From this step, we can construct a table with the limiting values of accepted voltage during different sags affecting the IM under test

- From the previous step, we can construct a sag tolerance curve for the IM under test

- Recommendations for readjusting the undervoltage relay based on the obtained results are given

- Parameters other than magnitude and duration are tested to complete the sensitivity analysis

\section{RESULTS AND DISCUSSON}

Startup and normal conditions: The results of this normal situation are shown in Fig. 4. From these results, the following remarks are noted:

- The motor speed accelerates gradually during the starting period till it reaches its operating speed at $1486 \mathrm{rpm}$ (slip $=1 \%$ approximately) in about $20 \mathrm{sec}$

- The starting current of the motor rushes to about 930 A (approximately $600 \%$ of full load), then the current decreases to its normal current of about 118 A (the motor operates at $80 \%$ of its full load) 

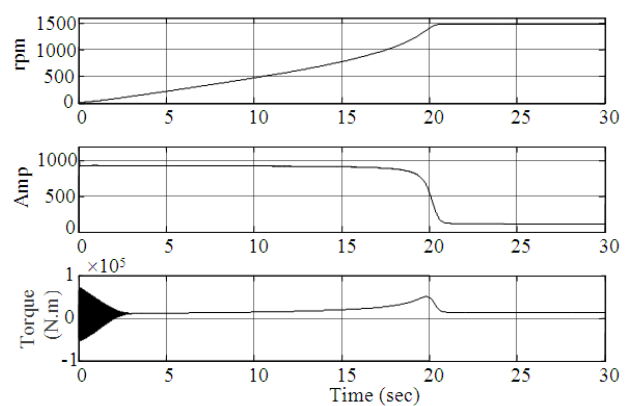

Fig. 4: Motor starting speed, current and torque
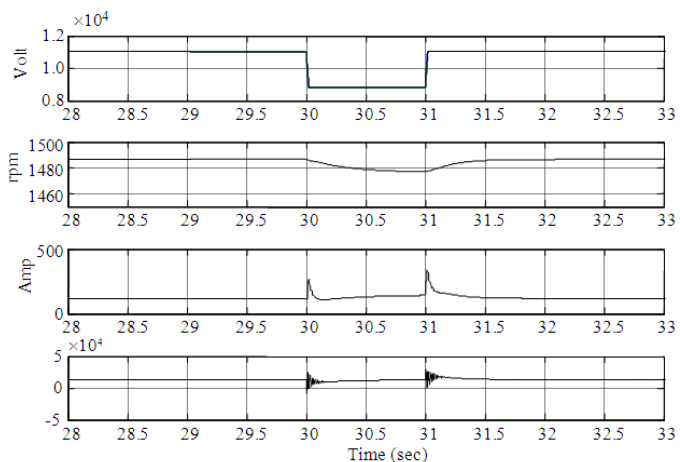

Fig. 5: Voltage, speed, current and torque for a sag to $80 \%, 1 \mathrm{sec}$

The motor is subjected to a pulsating torque from $+72,000$ to $-54,000$ N.m (peak to peak), for a period of 2 sec. After which, these pulsations decay and the motor operates with increasing unidirectional torque until it reaches its maximum value of 50,000 N.m in $20 \mathrm{sec}$. After which the motor torque intersects with the load torque at the operating point and the motor continues to deliver its normal torque of 13,000 N.m.

Sag to $80 \%$ p.u. and 1 sec: The motor is subjected to a three phase voltage sag with $80 \%$ magnitude and a duration of $1 \mathrm{sec}$. the sag starts at $\mathrm{t}=30 \mathrm{sec}$ and recovers $1 \mathrm{sec}$ later. This situation is presented in Fig. 5 and the following observations are noted:

- The speed drops to a value of $1477 \mathrm{rpm}$ (99\% of normal)

- The motor current increases on occurrence of the sag event reaching a value of 263 A $(222 \%$ of normal and $28 \%$ of starting), then drops eventually since a new operating point is reached. The motor continues running with increasing current till the voltage recover. At this instant, the initial operating point is reached and the motor draws a transient current of 337 A (285\% of normal and $36 \%$ of starting)

- The torque also shows two transients on sag occurrence and on full voltage recovery. The sag transient approaches 25,500 N.m (196\% of normal and $35 \%$ of starting), whereas the recovery transient approaches 30,000 N.m (230\% of normal and $42 \%$ of starting)

From these observations, it is clear that the under voltage relay settings are too conservative for the motor operation. The faculty consultants recommends that the under voltage relay settings should be readjusted and considered as a backup protection for other motor protection relays. To determine the appropriate values for the new settings, a thorough investigation of the motor behavior to different sags is carried out and is explained in the next step.

Tripping the IM without under voltage relay: The motor is subjected to three phase voltage sags at $t=30$ sec. The magnitude of the remaining voltage starts from 0.9 p.u. of the rated line voltage and decreases gradually in steps of 0.05 p.u. For each case, the duration of the sag will increase gradually till the motor trips, either by over current, locked rotor or mechanical protection. If no trigger signal comes out from the protection relays, the simulation continues till it ends at $\mathrm{t}=40 \mathrm{sec}$. The results of this step are presented in Table 4.

From Table 4, the following remarks are noted:

- The first sag event that trips the motor occurs for a sag to $65 \%$ p.u., for a duration of $4.5 \mathrm{sec}$. This shows that how the existing settings for the under voltage relay is too conservative and that many shutdowns due to motor tripping could have been avoidable

- As the remaining voltage during the sag decreases (voltage drop increases), the tripping time decreases. This is predicted as the criterion used to trip the motor is the inverse current-time characteristics. As the voltage decreases, the motor tries to supply the load by drawing higher current, triggering the over current protection

- All sags with remaining magnitude $40 \%$ of p.u. voltage and below result in severe transient torques that trigger the mechanical protection relays. The criterion here is the speed loss and it is of constant value. As the speed of the motor decreases below the threshold (95\% of the normal speed), the motor trips by mechanical protection 
Table 4: Limiting values tripping the IM

\begin{tabular}{llll}
\hline Sag voltage (p.u.) & Sag duration $(\mathrm{sec})$ & Motor tripped by & Limiting value \\
\hline 0.90 & $>10 \mathrm{sec}$ & No trip & - \\
0.80 & $>10 \mathrm{sec}$ & No trip & - \\
0.70 & $>10 \mathrm{sec}$ & No trip & - \\
0.65 & 4.488 & Over current & 181 \\
0.60 & 2.550 & Over current & $195 \mathrm{~A}$ \\
0.55 & 2.093 & Over current & $204 \mathrm{~A}$ \\
0.50 & 1.935 & Over current & $209 \mathrm{~A}$ \\
0.45 & 1.900 & Over current & $212 \mathrm{~A}$ \\
0.40 & 1.760 & Speed loss & $1410 \mathrm{rpm}$ \\
0.35 & 1.443 & Speed loss & $1410 \mathrm{rpm}$ \\
0.30 & 1.252 & Speed loss & $1410 \mathrm{rpm}$ \\
0.25 & 1.127 & Speed loss & $1410 \mathrm{rpm}$ \\
0.20 & 1.040 & Speed loss & $1410 \mathrm{rpm}$ \\
0.15 & 0.980 & Speed loss & $1410 \mathrm{rpm}$ \\
0.10 & 0.937 & Speed loss & $1410 \mathrm{rpm}$ \\
0.0 & 0.900 & Speed loss & $1410 \mathrm{rpm}$ \\
\hline
\end{tabular}

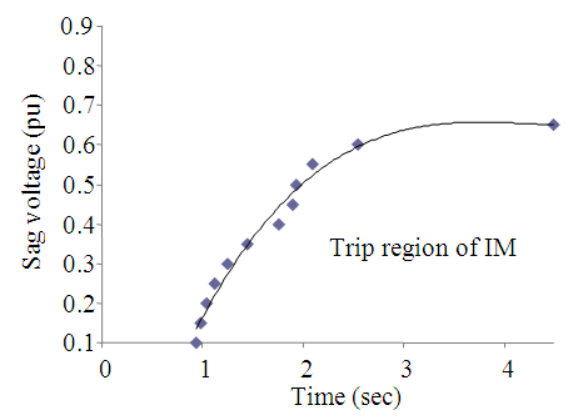

Fig. 6: Voltage tolerance curve for the IM

Voltage sag tolerance curve: The voltage acceptability curves are aides in the determination of whether the supply voltage to a load is acceptable for maintaining the continuity of a load process ${ }^{[8]}$. Figure 6 is the voltage sag tolerance curve (or ride through curve) of the IM under test. This curve may not necessarily apply to similar motors. It is expected that each motor (and any piece of equipment) has its own curve. The whole plant is sensitive to and may shut down as a result of, the most sensitive piece of equipment.

Note that this curve, constructed from Table 4, is based only on the two main parameters of the voltage sag; magnitude and duration. Other factors characterizing voltage sag such as unbalance of the three phases, point on the wave of sag occurrence and recovery, pre-sag voltage, loading percentage will be examined in the sensitivity analysis.

Recommended under voltage settings: Based on the results obtained from Table 4, the recommended settings for the under voltage relay are shown in Table 5 .

To verify these new settings, a new simulation with these values as the sag magnitude and duration is carried out and is shown in Fig. 7. It is clear that the current,
Table 5: Recommended under voltage settings

\begin{tabular}{|c|c|c|c|c|c|}
\hline \multicolumn{5}{|l|}{$\begin{array}{l}\text { Under voltage } \\
\text { Time }\end{array}$} & $\begin{array}{l}0.75 \text { p.u. } \\
1.5 \mathrm{sec}\end{array}$ \\
\hline able 6: Ef & o & eds sag & & & \\
\hline & Speed & $\begin{array}{l}\text { Sag } \\
\text { current }\end{array}$ & $\begin{array}{l}\text { Recovery } \\
\text { current }\end{array}$ & Sag torque & $\begin{array}{l}\text { Recovery } \\
\text { torque }\end{array}$ \\
\hline Three phase sag & 1473 & 323 & 405 & 28,000 & 33,500 \\
\hline Single phase sag & 1483 & 225 & 255 & 30,000 & 28,000 \\
\hline
\end{tabular}
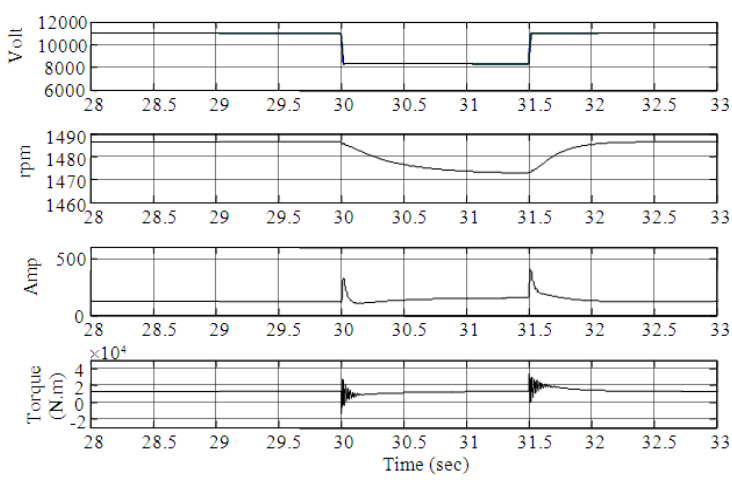

Fig. 7: Voltage, speed, current and torque for a sag to $75 \%, 1.5 \mathrm{sec}$

the torque and the speed do not approach their limiting values of starting. The speed drops to $1473 \mathrm{rpm}(99 \%$ of normal speed). The current transients are $323 \mathrm{~A}$ on sag start (273\% of normal and 35\% of starting) and 405 A on voltage recovery (342\% of normal and $43 \%$ of starting). The torque transients are $28,000 \mathrm{~N}$.m on sag start (215\% of normal and 38\% of starting) and 33,500 N.m on voltage recovery ( $258 \%$ of normal and $46 \%$ of starting).

Sensitivity analysis: Factors other than magnitude and duration may have effect on the response of the IM to the voltage sag.

Unbalanced voltage sag: Although the severity of the three phase voltage sag is expected to be more than that of the single phase sag, yet the latter is more frequent especially on the distribution circuits. The test is repeated for a sag on one phase and the results are shown in Table 6 and compared with results of Fig. 7. As expected, the single phase sag is less severe than the three phase one. This can be interpreted, as the full voltage present on the other two healthy phases will support the motor during the sag and at recovery ${ }^{[9]}$.

Effect of pre-sag voltage: As the supply voltage may range from 1.05-0.95 p.u., transient currents and torques may vary substantially for such tolerance. A summary of the IM response to these sags are shown in Table 7. 
Am. J. Applied Sci., 6 (8): 1626-1632, 2009

Table 7: Effect of pre-sag voltage

\begin{tabular}{llllll}
\hline & Speed & $\begin{array}{l}\text { Sag } \\
\text { current }\end{array}$ & $\begin{array}{l}\text { Recovery } \\
\text { current }\end{array}$ & $\begin{array}{l}\text { Sag } \\
\text { torque }\end{array}$ & $\begin{array}{l}\text { Recovery } \\
\text { torque }\end{array}$ \\
\hline Pre-sag 1.00 p.u. & 1473 & 323 & 405 & 28,000 & 33,500 \\
Pre-sag 1.05 p.u. & 1473 & 385 & 405 & 32,000 & 33,500 \\
Pre-sag 0.95 p.u. & 1473 & 264 & 405 & 24,400 & 33,500 \\
\hline
\end{tabular}

Table 8: Effect of loading conditions

\begin{tabular}{llllll}
\hline & Speed & $\begin{array}{l}\text { Sag } \\
\text { current }\end{array}$ & $\begin{array}{l}\text { Recovery } \\
\text { current }\end{array}$ & $\begin{array}{l}\text { Sag } \\
\text { torque }\end{array}$ & $\begin{array}{l}\text { Recovery } \\
\text { torque }\end{array}$ \\
\hline Full load operation & 1473 & 323 & 405 & 28,000 & 33,500 \\
3/4 load operation & 1481 & 317 & 380 & 26,000 & 30,000 \\
$1 / 2$ load operation & 1489 & 315 & 360 & 24,000 & 26,000 \\
\hline
\end{tabular}

Comparing with the reference 1.0 p.u. pre-sag, there is almost no change in the IM speed. However, transient currents and torques on occurrence of sag differ noticeably; transient currents and torques for voltage difference of $20 \%$ are less than those for voltage difference of $30 \%$. This may explain why the IM may trip (by the over current relay) on a voltage drop to $75 \%$ lasting for $1.5 \mathrm{sec}$ in case of pre-sag voltage equals 1.05 p.u., while the same IM may survive the same voltage sag in case of pre-sag voltage equals 0.95 p.u. Similar results are represented in ${ }^{[10]}$.

Operating the motor at $3 / 4$ and $1 / 2$ of the full load: In some cases, the industrial process operates the motor at $3 / 4$ or $1 / 2$ its full load. Note that the basic parameters of the motor are now changed.

In case of $3 / 4$ load, there will exist a new operating point, for which the normal speed increases to 1489 $\mathrm{rpm}$, the normal current decreases to $95 \mathrm{~A}$ and the normal torque is reduced to 10,000 N.m.

In case of $1 / 2$ load, the normal speed increases to $1493 \mathrm{rpm}$, the normal current decreases to $73 \mathrm{~A}$ and the normal torque is reduced to 7500 N.m.

The IM response to both situations is presented in Table 8. It is clear that the possibility of the IM to survive a sag increases by decreasing the loading conditions.

Effect of source harmonic distortion: Consider again the test signal of Fig. 7. Assume that there are some harmonics present at the supply bus. Normally triplen harmonics are eliminated in the power transformer. What really matters is the distortion level of the 5th and sometimes the 7 th harmonics. Now, if we introduce a 5 th harmonic with $20 \%$ p.u. and a 7 th with $15 \%$ p.u. to our test signal, the results will be that of Table 9 .

Minor differences are there between the two results, with the exception of bold torque. This boldness refers actually to the power frequency oscillations in the motor torque due to presence of harmonic distortion.
Table 9: Effect of harmonic distortion

\begin{tabular}{llllll}
\hline & Speed & $\begin{array}{l}\text { Sag } \\
\text { current }\end{array}$ & $\begin{array}{l}\text { Recovery } \\
\text { current }\end{array}$ & $\begin{array}{l}\text { Sag } \\
\text { torque }\end{array}$ & $\begin{array}{l}\text { Recovery } \\
\text { torque }\end{array}$ \\
\hline Reference sag & 1473 & 323 & 405 & 28,000 & 33,500 \\
Harmonic polluted sag & 1469 & 325 & 405 & 29,000 & 34,200 \\
\hline
\end{tabular}

Table 10: Effect of point on the wave

\begin{tabular}{llllll}
\hline & Speed & $\begin{array}{l}\text { Sag } \\
\text { current }\end{array}$ & $\begin{array}{l}\text { Recovery } \\
\text { current }\end{array}$ & $\begin{array}{l}\text { Sag } \\
\text { torque }\end{array}$ & $\begin{array}{l}\text { Recovery } \\
\text { torque }\end{array}$ \\
\hline Reference sag & 1473 & 323 & 405 & 28,000 & 33,500 \\
Phase shifted & 1473 & 180 & 284 & 28,000 & 33,500 \\
\hline
\end{tabular}

Point on the wave: In all the previously simulated sags, the sag starts at $\mathrm{t}=30 \mathrm{sec}$, which corresponds to zero phase angle. Moreover, the voltage recovers at $t=31.5$ sec, again corresponding to zero angle. Consider now that the sag occurs at any instant (angle other than zero) which is almost the actual case and recovers at a different angle. A new set of simulations is carried out with the same sag magnitude and duration, but at different instants. Comparison between the reference sag and the most significant case (with angle $=90^{\circ}$ ) is given in Table 10.

It is clear that when the sag occurs at $90^{\circ}$ angle in the voltage signal, this corresponds to near zero angle in the current signal, current transients in this case are minimum.

\section{CONCLUSION}

The influences of voltage sags on the behavior of induction motors are thoroughly investigated. Upon the occurrence of a voltage sag, the induction motor speed drops, the motor is subjected to transient currents and torques depending on the sag magnitude, duration and the motor and load parameters. Upon voltage recovery, the motor is subjected once more to transient currents and torques, exceeding in many cases the previous transients, but still lower than transients during starting process.

The following are the main observations of this research:

- Three-phase voltage sags are the most severe events and should be taken in consideration for any evaluation

- Under-voltage protection with fixed magnitude and duration should not be the main protection relay of the induction motors

- Transient currents are directly proportional to the voltage drop, not to the remaining voltage magnitude

- Sags occurring at the voltage wave zero crossing are the most severe and should be taken in consideration for any evaluation 
- Motors operating at lower loading ratios are less sensitive to voltage sags

- Harmonic distortion in the supply source has no noticeable effect on the motor performance during sags

- $\quad$ Readjusting of the protection relay settings may be adequate to counteract voltage sags. No additional power conditioning equipment is required

\section{ACKNOWLEDGMENT}

The researchers would like to thank Prof. Dr. Abdel-Mon'em Moussa, the head of the consultant team of the Faculty of Engineering, Alexandria University.

\section{REFERENCES}

1. IEEE Xplore Press, 1995. IEEE recommended practice for monitoring electric power quality. http://ieeexplore.ieee.org/xpl/freeabs_all.jsp?tp=\&i snumber $=10032$ \&arnumber $=475495 \&$ punumber $=3$ 366

2. International Electrotechnical Commission, 1992. IEC TR 61000-2-3 Electromagnetic Compatibility (EMC)-Part 2: Environment-section 3: Description of the environment-radiated and non-networkfrequency-related conducted phenomena. http://electronics.ihs.com/document/abstract/UYR ZCAAAAAAAAAAA

3. IEEE Xplore Press, 1998. IEEE recommended practice for the design of reliable industrial and commercial power systems. http://ieeexplore.ieee.org/xpl/freeabs_all.jsp?arnum ber $=757619$

4. Das, J.C., 1990. Effects of momentary voltage dips in the operation of induction and synchronous motors. IEEE Trans. Ind. Appli., 26: 711-718. DOI: $10.1109 / 28.55998$
5. Milanovic, J.V., M.T. Aung and S.C. Vegunta, 2008. The influence of induction motors on voltage sag propagation-part I: Accounting for the change in sag characteristics. IEEE Trans. Power Delivery, 23: 1063-1071. DOI: 10.1109/TPWRD.2007.915846

6. Gomez, J.C., M.M. Morcos, C.A. Reineri and G.N. Campatelli, 2002. Behavior of induction motor due to voltage sags and short interruptions. IEEE Trans. Power Delivery, 17: 434-440. DOI: 10.1109/61.997914

7. Leiria, A., P. Nunes, A. Morched and M.T. Correia de Barros, 2006. Induction motor response to voltage dips. Proceeding of the International Conference on Power System Transients, Sept. 28, New Orleans, USA., pp: 676-680. http://cat.inist.fr/?aModele $=$ afficheN\&cpsidt $=1768$ 5117

8. Kyei, J., R. Ayyanar, G. Heydt, R. Thallam and J. Blevins, 2002. The design of power acceptability curves. IEEE Trans. Power Delivery, 17: 828-833. DOI: 10.1109/TPWRD.2002.1022811

9. Guasch, L., F. Corcoles and J. Pedra, 2004. Effects of symmetrical and unsymmetrical voltage sags on induction machines. IEEE Trans. Power Delivery, 19: 774-782. DOI: 10.1109/TPWRD.2004.825258

10. Carlsson, F., 2005. Before and during voltage sags. IEEE Ind. Appli. Mag., 11: 39-46. DOI: 10.1109/MIA.2005.1405825 